EXTENDED REPORT

\title{
Accelerated atherosclerosis in patients with Wegener's granulomatosis
}

\author{
K de Leeuw, J-S Sanders, C Stegeman, A Smit, C G Kallenberg, M Bijl

See end of article for authors' affiliations

Correspondence to:

Ms Karina de Leeuw Department of Internal Medicine, Division of Clinical Immunology, University Hospital, PO Box $30.001,9700$ RB Groningen, Netherlands; k.de.leeuw@int.azg.nl

Accepted

10 September 2004

Published Online First

16 September 2004

\begin{abstract}
Background: Several autoimmune disorders are complicated by excess cardiovascular disease. In addition to traditional risk factors, non-traditional risk factors such as endothelial activation and excessive vascular remodelling might be determinants of the progression of atherosclerosis in patients with an autoimmune disease.

Objective: To evaluate whether patients with Wegener's granulomatosis (WG) have an increased prevalence of atherosclerosis and to determine predisposing factors.

Methods: 29 WG patients (19 men; mean (SD) age, 53 (14) years) with inactive disease and 26 controls (16 men; age 53 (15) years) were studied. Common carotid intima-media thickness (IMT) was measured by ultrasound. In all individuals traditional risk factors for cardiovascular disease were determined. High sensitivity $\mathrm{C}$ reactive protein ( $\mathrm{hs} C \mathrm{RP}$ ) was measured. Endothelial activation was assessed by measuring thrombomodulin, vascular cell adhesion molecule-1, and von Willebrand factor. As a marker of vascular remodelling matrix metalloproteinases (MMP-3 and MMP-9) and TIMP-1 were measured.

Results: IMT was increased in WG patients compared with controls $(p<0.05)$. No differences in traditional risk factors and endothelial activation markers between patients and controls were found. Levels of hsCRP, MMPs, and TIMP-1 were increased in WG patients $(p<0.05)$.

Conclusions: Increased IMT found in WG patients cannot be explained by an increased prevalence of traditional risk factors. Although endothelial activation markers in WG patients with inactive disease were not increased, the raised levels of hsCRP, MMPs, and TIMP-1 suggest that enhanced inflammation and excessive vascular remodelling are contributing factors in the development of accelerated atherosclerosis in WG.
\end{abstract}

$\mathrm{T}$ he pathogenesis of atherosclerosis is complex and still not completely understood. It is regarded currently as an inflammatory disease. ${ }^{1-4}$ This is supported by various large scale prospective epidemiological studies showing that increased serum levels of inflammatory markers are predictive of future cardiovascular disease. ${ }^{56}$ One of the first steps in the development of atherosclerosis is endothelial activation, which results in increased expression of adhesion molecules on the endothelial cell, promoting adherence of monocytes. After transmigration into the vessel wall, monocytes become macrophages, which will develop into so called foam cells. The process continues with lipid accumulation, release of cytokines, and proliferation of smooth muscle cells, resulting in plaque formation.

Many risk factors for cardiovascular disease, traditional and non-traditional, contribute to endothelial activation as one of the initial steps. Traditional risk factors like smoking, hypertension, and dyslipidaemia disturb vascular homeostasis, resulting in endothelial activation. Non-traditional risk factors, such as inflammation, are also involved in these early steps of development of atherosclerosis. C reactive protein has been shown to be an independent prognostic marker for cardiovascular disease. ${ }^{7}$

Inflammation is also one of the hallmarks of systemic autoimmune diseases. These diseases_-such as rheumatoid arthritis and systemic lupus erythematosus (SLE)-are complicated by excess cardiovascular morbidity and mortality which cannot be explained by traditional risk factors alone. ${ }^{8-13}$ Endothelial activation, which is common in systemic vasculitides such as Wegener's granulomatosis (WG) and is probably induced by autoantibodies, ${ }^{14}{ }^{15}$ may be one explanation for this increased risk. Antineutrophil cytoplasmic antibodies (ANCA), particularly those directed to proteinase 3 (PR3-ANCA), are a marker autoantibody for WG, a disease characterised by necrotising vasculitis affecting small to medium sized vessels. ${ }^{16}$ ANCA can activate endothelial cells, as shown in vitro. ${ }^{17}$ Endothelial activation may also occur in vivo, as demonstrated by increased serum levels of soluble intracellular adhesion molecule 1, vascular cell adhesion molecule 1 (VCAM-1), and E-selectin. ${ }^{18}$ Therefore, endothelial cell dysfunction and eventually atherosclerosis can be expected to occur in WG. Indeed, two studies have described endothelial cell dysfunction in systemic vasculitis. ${ }^{19} 20$ Furthermore, Booth et al demonstrated increased arterial stiffness, a reflection of endothelial cell dysfunction, in ANCA associated systemic vasculitis, which correlated with the degree of active inflammation. ${ }^{21}$

Based on these data we hypothesised that atherosclerosis, as measured by carotid intima-media thickness (IMT), should have an increased prevalence among WG patients, which would not be explained by the presence of traditional risk factors for cardiovascular disease. We evaluated whether disease related factors were implicated in atherosclerosis. Furthermore, as vascular remodelling is an essential feature of the development of atherosclerosis, ${ }^{22-24}$ we assessed levels of matrix metalloproteinases (MMP) and the endogenous tissue inhibitor of matrix metalloproteinases (TIMP) as markers for vascular remodelling.

Abbreviations: ANCA, antineutrophil cytoplasmic antibodies; BVAS, Birmingham vasculitis activity score; hsCRP, high sensitivity $C$ reactive protein; IMT, intima-media thickness; MMP, matrix metalloproteinase; TIMP, tissue inhibitor of metalloproteinase; VCAM-1, vascular cell adhesion molecule-1; vWF, von Willebrand factor; WG, Wegener's granulomatosis; WTS, wall track system 
Table 1 Characteristics of patients and controls

\begin{tabular}{|c|c|c|c|}
\hline Characteristic & Patients $(n=29)$ & Controls $(n=26)$ & p Value \\
\hline Age (y) & $53.2(13.8)$ & $53.2(14.5)$ & NS \\
\hline Male sex (n (\%)) & $19(66 \%)$ & $16(62 \%)$ & NS \\
\hline Body mass index $\left(\mathrm{kg} / \mathrm{m}^{2}\right)$ & $25.6(3.3)$ & $24.8(2.8)$ & NS \\
\hline \multicolumn{4}{|l|}{ Blood pressure $(\mathrm{mm} \mathrm{Hg})$} \\
\hline Systolic & $115(17)$ & $116(17)$ & NS \\
\hline Diastolic & $69(12)$ & $72(8)$ & NS \\
\hline Smoking $(n)$ & 1 & 6 & NS \\
\hline Pack years for smokers & 0.5 & $4.5(3 \text { to } 8)^{*}$ & NS \\
\hline Diabetes (n) & 1 & 0 & NS \\
\hline \multicolumn{4}{|l|}{ Cholesterol } \\
\hline Total (mmol/l) & $5.58(0.90)$ & $5.58(1.14)$ & NS \\
\hline $\mathrm{LDL}(\mathrm{mmol} / \mathrm{l})$ & $3.77(0.79)$ & $3.67(1.10)$ & \\
\hline $\mathrm{HDL}(\mathrm{mmol} / \mathrm{l})$ & $1.07(0.33)$ & $1.17(0.26)$ & \\
\hline Triglycerides (mmol/l) & $1.73(0.97)$ & $2.03(2.36)$ & \\
\hline Family history of CVD (n (\%)) & $6(21 \%)$ & $8(31 \%)$ & NS \\
\hline Antihypertensive agents ( $\mathrm{n}$ ) & 5 & 0 & NS \\
\hline HMG-CoA inhibitors (n) & 4 & 0 & NS \\
\hline
\end{tabular}

\section{METHODS \\ Patients}

We studied 29 consecutive patients fulfilling the American College of Rheumatology (ACR) criteria for $\mathrm{WG}^{25}$ and attending our outpatient clinic at the University Hospital Groningen. Pregnancy and active disease were exclusion criteria. Disease activity was assessed by the Birmingham vasculitis activity score (BVAS), and active disease was defined as a BVAS of $>1 .{ }^{26}$ We recruited healthy age and sex matched volunteers as controls. The local research ethics committee gave approval for the study, and informed consent was obtained from each participant.

Information was obtained from all subjects with respect to the traditional risk factors for cardiovascular disease, including blood pressure, body mass index, lipid levels, smoking status, diabetes, and family history of cardiovascular disease (considered positive if first degree relatives suffered from cardiovascular disease before 60 years of age). The use of HMG-CoA inhibitors and antihypertensive agents was recorded.

We also assessed disease related factors that might influence the development of atherosclerosis. As a measure of overall disease burden, cumulative BVAS was calculated by summing the BVAS scores of each exacerbation. In addition, we recorded cumulative prednisolone doses, proteinuria, and creatinine clearance.

\section{Blood analyses}

Plasma lipid concentrations (cholesterol, high density lipoprotein, low density lipoprotein, and triglycerides) were measured by routine techniques.

Additional serum and plasma samples for determination of levels of markers of endothelial activation, inflammation, and vascular remodelling were stored at $-20^{\circ} \mathrm{C}$ until analysis. Serum levels of VCAM-1 (R\&D Systems, Abingdon, UK), thrombomodulin (Diaclone, Besançon, France), and MMP-3 (Amersham Biosciences, Uppsala, Sweden) were measured according to the manufacturer's instructions. Von Willebrand factor (vWF), hsCRP, MMP-9, and TIMP-1 were determined using in-house enzyme linked immunosorbent assays (ELISAs).

For the determination of serum levels of $\mathrm{vWF}$, microplates of high protein binding capacity (Nunc, Copenhagen, Denmark) were coated with $1 \mu \mathrm{g} / \mathrm{ml}$ rabbit antihuman vWF (DakoCytometion, Glostrup, Denmark) diluted in phosphate buffered saline ( $\mathrm{pH} 7.2$ ) for 12 hours at $4^{\circ} \mathrm{C}$. After washing, the plates were incubated with sera (in two dilutions, 1:100 and $1: 200)$ and a serial twofold dilution of the reference pool made of 60 healthy volunteers for two hours at room temperature. After washing, the plates were incubated with peroxidase conjugated rabbit antihuman vWF (1:3000, DakoCytometion) at room temperature. After one hour the plates were washed and the chromogen O-phenylenediamine (OPD, DakoCytometion) in substrate solution and hydrogen peroxide was added to each well. The colour reaction was stopped by adding $1 \mathrm{M} \mathrm{H}_{2} \mathrm{SO}_{4}$, and the absorption was read at $492 \mathrm{~nm}$ in an Emax microplate reader. The concentrations of the samples were calculated against the standard curve by SOFTmax Pro software (Molecular Devices, Sunnyvale, California, USA).

Plasma $\mathrm{C}$ reactive protein was determined as described before. ${ }^{27}$ Briefly, microtitre plates (Greiner, Alphen a/d Rijn, Netherlands) were coated overnight with rabbit antihuman C reactive protein (DakoCytometion). Serial fourfold dilutions of plasma samples (starting at 1:20) and standards were added to the plates after washing. After one hour of incubation the plates were washed and a peroxidase labelled rabbit antihuman $\mathrm{C}$ reactive protein antibody (DakoCytometion) was added to the plate. The colour reaction was achieved as described below.

To detect MMP-9 and TIMP-1, plates were precoated with $\mathrm{F}(\mathrm{ab})_{2}$ goat antimouse immunoglobulin (Jackson Immunoresearch Labs, West Grove, Pennsylvania, USA), $\mathrm{l} \mu \mathrm{g} / \mathrm{ml}$ diluted in $0.1 \mathrm{M}$ carbonate buffer $(\mathrm{pH}=9.6)$, for 48 hours at $4^{\circ} \mathrm{C}$. After washing, plates were coated with

Table 2 Characteristics of patients with Wegener's granulomatosis

\begin{tabular}{|c|c|}
\hline Characteristics & All $(n=29)$ \\
\hline Disease duration (months) & $59(26$ to 124$)$ \\
\hline Generalised disease (n (\%)) & $20(69 \%)$ \\
\hline Proteinuria (mg/l) & $0.3(0$ to 0.5$)$ \\
\hline Creatinine clearance $(\mathrm{ml} / \mathrm{min})$ & $83(29)$ \\
\hline Patients with exacerbation ( $\mathrm{n}$ ) & 17 \\
\hline Number of exacerbations (median, range) & $1(7)$ \\
\hline Cumulative BVAS & $34.7(16.8)$ \\
\hline Cumulative BVAS/disease duration in months & $0.84(0.74)$ \\
\hline Prednisolone use (n) & 27 \\
\hline Cumulative prednisolone dose $(\mathrm{g})$ & $15(10$ to 29$)$ \\
\hline Cumulative dose ( $\mathrm{mg} /$ disease duration in months) & 324 (117 to 543$)$ \\
\hline \multicolumn{2}{|c|}{$\begin{array}{l}\text { Values are mean (SD) or median ( } 25 \text { th to } 75 \text { th centile) unless stated } \\
\text { otherwise. } \\
\text { BVAS, Birmingham vasculitis activity score. }\end{array}$} \\
\hline
\end{tabular}




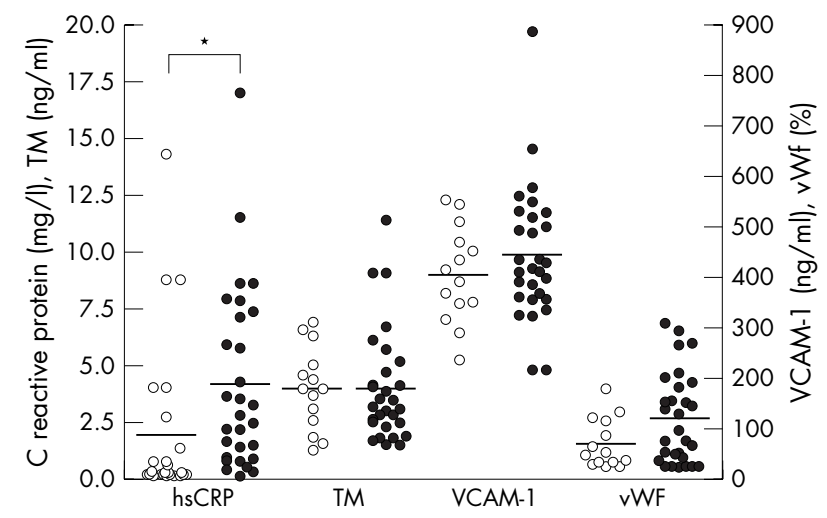

Figure 1 Inflammation and endothelial activation markers. Empty circles represent controls, filled circles represent patients with Wegener's granulomatosis.

$0.1 \mu \mathrm{g} / \mathrm{ml}$ mouse antihuman MMP-9 or $0.5 \mu \mathrm{g} / \mathrm{ml}$ mouse antihuman TIMP-1 (both R\&D Systems). Standards (recombinant MMP-9 or TIMP-1; R\&D Systems) in eight serial dilutions and serum samples in four serial dilutions in high performance ELISA (HPE) buffer (Sanquin, Amsterdam, Netherlands) were incubated for one hour at room temperature. After washing, bound MMP-9 or TIMP-1 was detected by one hour's incubation with $50 \mathrm{ng} / \mathrm{ml}$ biotinylated rabbit antihuman MMP-9 or $12.5 \mathrm{ng} / \mathrm{ml}$ biotinylated rabbit antihuman TIMP-1 (both R\&D Systems), respectively. After washing, samples were incubated with $0.125 \mu \mathrm{g} / \mathrm{ml}$ streptavidin poly-HRP (Sanquin) for 30 minutes and the colour reaction was achieved with tetramethylbenzidine (TMB) (Roth, Karlsruhe, Germany). The reaction was stopped by adding $1 \mathrm{M} \mathrm{H}_{2} \mathrm{SO}_{4}$, the plates were scanned at $450-575 \mathrm{~nm}$, and the concentrations were calculated against the standard curves.

\section{Measurements of intima-media thickness}

Details of the method used in this study have been described by de Groot et al..$^{28}$ In brief, IMT was determined in the far wall of the left common carotid artery approximately $1 \mathrm{~cm}$ proximal to the bulbus at three different positions. Acuson 128XP ultrasound with $7 \mathrm{MHz}$ linear array transducers was carried out in all 29 patients and in 21 controls (Acuson Corporation, Mountain View, California, USA). A B mode image was obtained of the common carotid artery, after which a probe was positioned perpendicular to the far wall, showing an intima-media complex over approximately $1 \mathrm{~cm}$. Mean IMT (m-IMT; the mean of the three measurements) and the maximum IMT (M-IMT; the highest IMT value found among the segment studied) were calculated. Maximum IMT was used to determine correlations with other variables.

In addition, IMT of the common carotid artery was measured using the wall track system (WTS). This technique measures IMT at a discrete arterial position. The far wall of the left common carotid artery was assessed three times $1 \mathrm{~cm}$ proximal to the carotid bifurcation. Recorded data were

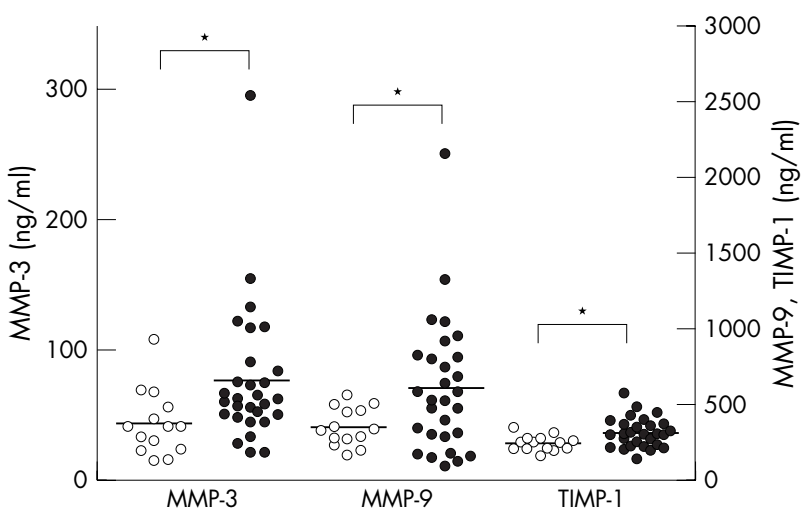

Figure 2 Markers of vascular remodelling. Empty circles represent controls, filled circles represent patients with Wegener's granulomatosis.

processed using WTS 2.0 software (Pie Medical, Maastricht, Netherlands) and the mean value was used for further analyses, expressed as IMT-WTS. Adequate data of all 29 patients and 19 controls were available for analyses.

IMT was considered to be increased when it exceeded $0.8 \mathrm{~mm}$ at the age of 50 and $0.9 \mathrm{~mm}$ when age was over $50 .{ }^{29}$

\section{Statistical methods}

Except when stated otherwise, values are expressed as mean (SD) when variables were normally distributed. In case of a non-normal distribution, data are reported as median (25th to 75 th centile). Comparison between patients and controls and between patients with and without increased IMT were made by two sample $t$ tests or Mann-Whitney U tests for continuous variables, and by $\chi^{2}$ analysis for categorical variables. The univariate correlation between IMT and other categorical variables was assessed by the Pearson correlation coefficient when variables were normally distributed. Otherwise, the Spearman correlation coefficient was used. A two sided $p$ value of $<0.05$ was considered significant.

\section{RESULTS}

\section{Characteristics of patients and controls}

The demographic characteristics and traditional cardiovascular risk factors of all subjects are shown in table 1. The patients and controls were similar with respect to age, sex, blood pressure, smoking habits, body mass index, lipid levels, prevalence of diabetes, and a positive family history of cardiovascular disease. Five patients (17\%) used antihypertensive drugs and four (14\%) used HMG-CoA inhibitors. None of the 26 controls used antihypertensive agents or HMG-CoA inhibitors.

\section{Disease related factors}

To study the relation between disease characteristics and the development of atherosclerosis, several disease related factors were recorded (table 2). The duration of disease from diagnosis of WG until the point of IMT measurement was 59 (26 to 124) months. Twenty patients had generalised

Table 3 Intima-media thickness of patients and controls

\begin{tabular}{|c|c|c|c|c|}
\hline \multicolumn{2}{|l|}{ IMT } & \multirow{2}{*}{$\begin{array}{l}\text { Patients }(n=29) \\
0.81(0.21)\end{array}$} & \multirow{2}{*}{$\begin{array}{l}\text { Controls }(n=26) \\
0.66(0.12), n=19\end{array}$} & \multirow{2}{*}{$\begin{array}{l}p \text { Value } \\
0.004\end{array}$} \\
\hline WTS (M mode) & IMT (mm) & & & \\
\hline Acuson (B mode) & m-IMT (mm) & $0.72(0.16)$ & $0.66(0.13), n=21$ & 0.129 \\
\hline & M-IMT (mm) & $0.86(0.17)$ & $0.77(0.11), n=21$ & 0.035 \\
\hline
\end{tabular}


disease and 17 had experienced at least one exacerbation. Proteinuria was 0.3 (0.0 to 0.5 ) g/l and creatinine clearance 83 (29) $\mathrm{ml} / \mathrm{min}$. Cumulative prednisolone dose taken by 27 patients was 15 (10 to 29 ) $\mathrm{g}$.

\section{Intima-media thickness}

As a marker of early atherosclerosis IMT was assessed by $\mathrm{B}$ mode and $\mathrm{M}$ mode ultrasound (table 3). Using Acuson (B mode), maximum IMT (M-IMT)-measured over an arterial segment in the common carotid artery of approximately $1 \mathrm{~cm}$-was increased in WG patients $(\mathrm{p}<0.05)$, whereas mean IMT (m-IMT) over this segment did not differ between controls and patients.

Measured by WTS ( $M$ mode), providing an accurate value for IMT at a discrete arterial position, IMT was increased in patients with WG $(\mathrm{p}<0.01)$.

\section{Blood analyses}

To investigate whether endothelial activation in WG patients with inactive disease was present, serum levels of endothelial activation markers (thrombomodulin, VCAM-1, and vWF) were measured. Although differences were not significant between patients and controls, serum vWF tended to be higher in the patients, at 95 (38 to 185) v 49 (30 to 116) ng/ml $(\mathrm{p}=0.11)$. Compared with controls, plasma levels of hsCRP were raised in WG patients, at $2.79(0.89$ to 7.22$) v 0.18(0.16$ to 0.66$) \mathrm{mg} / \mathrm{l}(\mathrm{p}<0.01$; fig $\mathrm{l})$.

Concentrations of MMP-3, MMP-9, and TIMP-1, reflecting vascular remodelling, were significantly increased in WG patients compared with controls $(\mathrm{p}<0.01)$ (fig 2$)$.

\section{Univariate analyses of risk factors}

To determine predisposing variables, univariate regression analyses were undertaken to detect correlations between M-IMT and traditional risk factors for cardiovascular disease on the one hand, and non-traditional risk factors and disease related factors on the other (table 4). Both in controls and patients, M-IMT was correlated with age, as shown in fig 3 $(r=0.57, \mathrm{p}=0.002$ and $r=0.48, \mathrm{p}=0.028$, respectively). Furthermore, in controls a positive correlation was found between M-IMT and body mass index $(r=0.56, \mathrm{p}=0.008)$, systolic blood pressure $(r=0.51, \mathrm{p}=0.018)$, and diastolic blood pressure $(r=0.52, \mathrm{p}=0.016)$. In the patients, M-IMT was negatively correlated with the number of exacerbations $(r=-0.41, \mathrm{p}=0.035)$. None of the other variates was significantly correlated with M-IMT.

\section{Comparison of risk factors for cardiovascular disease in WG patients with and without increased IMT}

By dividing the patient group in those with $(\mathrm{n}=17)$ and without $(\mathrm{n}=12)$ increased IMT, we evaluated which factors

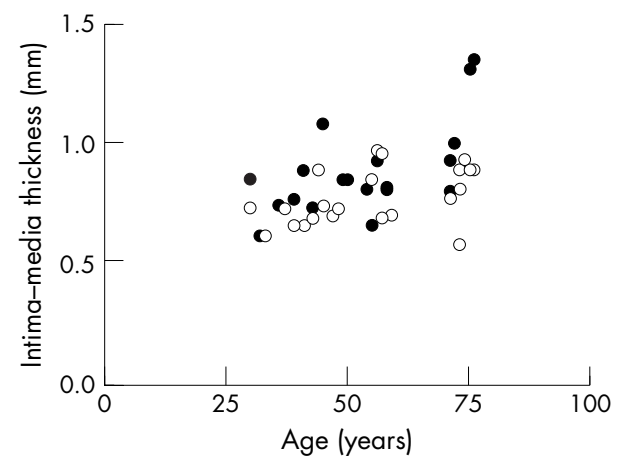

Figure 3 Correlation between intima-media thickness and age in controls and patients. Empty circles represent controls, filled circles represent patients with Wegener's granulomatosis.
Table 4 Correlations between maximum intima-media thickness and other variables

\begin{tabular}{|c|c|c|c|c|}
\hline \multirow[b]{2}{*}{ Variable } & \multicolumn{2}{|c|}{ Patients ( $n=29$ ) } & \multicolumn{2}{|c|}{ Controls $(n=26$ ) } \\
\hline & $r$ & p Value & $r$ & p Value \\
\hline Age & 0.57 & 0.00 & 0.48 & 0.03 \\
\hline $\begin{array}{l}\text { Body mass index } \\
\text { Blood pressure }\end{array}$ & 0.00 & 0.98 & 0.56 & 0.01 \\
\hline Systolic & 0.27 & 0.18 & 0.51 & 0.02 \\
\hline Diastolic & 0.28 & 0.16 & 0.52 & 0.02 \\
\hline \multicolumn{5}{|l|}{ Cholesterol } \\
\hline Total & -0.31 & 0.11 & 0.38 & 0.09 \\
\hline LDL & -0.20 & 0.32 & 0.27 & 0.24 \\
\hline $\mathrm{HDL}$ & -0.26 & 0.20 & -0.17 & 0.47 \\
\hline Triglyceride & 0.19 & 0.35 & 0.09 & 0.72 \\
\hline $\mathrm{TM}$ & -0.04 & 0.85 & 0.13 & 0.67 \\
\hline VCAM-1 & 0.23 & 0.26 & -0.01 & 0.98 \\
\hline WWF & 0.13 & 0.51 & -0.05 & 0.86 \\
\hline $\mathrm{H}_{\mathrm{s}} \mathrm{CRP}$ & 0.14 & 0.49 & -0.17 & 0.57 \\
\hline MMP-3 & -0.21 & 0.30 & -0.11 & 0.71 \\
\hline MMP-9 & -0.13 & 0.53 & 0.08 & 0.79 \\
\hline TIMP-1 & 0.01 & 0.96 & -0.31 & 0.23 \\
\hline Disease duration & 0.22 & 0.27 & & \\
\hline Proteinuria & 0.05 & 0.80 & & \\
\hline Creatinine clearance & -0.12 & 0.54 & & \\
\hline Number of & -0.41 & & & \\
\hline exacerbations & & 0.04 & & \\
\hline Cumulative BVAS & -0.27 & 0.18 & & \\
\hline Prednisolone* & 0.06 & 0.75 & & \\
\hline
\end{tabular}

*Cumulative dose.

BVAS, Birmingham vasculitis activity score; $\mathrm{HDL}$, high density lipoprotein; hs $C R P$, high sensitivity $C$ reactive protein; $L D L$, low density lipoprotein; MMP, matrix metalloproteinase; TIMP, tissue inhibitor of metalloproteinase; TM, thrombomodulin; VCAM-1, vascular cell adhesion molecule-1; vWF, von Willebrand factor.

were more prevalent in those with increased IMT (table 5). No differences in any of the variables were found, except for the number of exacerbations, which was higher in the group of patients with a normal IMT $(p=0.03)$.

We also compared WG patients with an increased IMT with the controls. Except for HDL levels, which were lower in the patients, no differences in traditional risk factors were found. Patients used more HMG-CoA inhibitors $(p<0.05)$ than controls. hsCRP, MMP-3, MMP-9, and TIMP-1 values were significantly higher in patients with an increased IMT.

\section{DISCUSSION}

In this study, we showed that increased IMT was a sign of accelerated development of atherosclerosis in WG patients, assessed during inactive disease, compared with controls. This difference could not be explained by traditional risk factors, suggesting that the disease itself contributes to the development of atherosclerosis. Patients had raised levels of hsCRP, MMP-3, MMP-9, and TIMP-1, reflecting increased systemic inflammation and enhanced vascular remodelling.

Previous studies have shown premature atherosclerosis in autoimmune diseases such as SLE and rheumatoid arthritis. Roman et al found an association of atherosclerosis with a longer duration of disease, a higher damage index score, and less aggressive immunosuppressive treatment, arguing strongly for chronic inflammation as an atherogenic factor in patients with SLE. ${ }^{12}$ Endothelial dysfunction, which may lead to atherosclerosis, has been demonstrated in systemic vasculitis. ${ }^{19-21}$ The present study shows for the first time an increased prevalence of atherosclerosis in patients with systemic vasculitis.

To measure the extent of atherosclerosis we used ultrasound of the common carotid artery, as this segment can be assessed with high reproducibility, showing less variability than other segments, and reveals the presence of early atherosclerosis. ${ }^{30}$ We chose to use two different ultrasound 
Table 5 Characteristics of patients with Wegener's granulomatosis, with and without increased intima-media thickness, and controls

\begin{tabular}{|c|c|c|c|}
\hline Characteristic & Normal IMT $(n=12)$ & Increased IMT $(n=17)$ & Controls \\
\hline Age $(y)$ & $47.6(13.8)$ & $57.2(12.7)$ & $53.2(14.5)$ \\
\hline Male sex (n (\%)) & $6(50 \%)$ & $13(76 \%)$ & $16(62 \%)$ \\
\hline Body mass index $\left(\mathrm{kg} / \mathrm{m}^{2}\right)$ & $24.6(2.2)$ & $26.2(3.8)$ & $24.8(2.8)$ \\
\hline \multicolumn{4}{|l|}{ Blood pressure $(\mathrm{mm} \mathrm{Hg})$} \\
\hline Systolic & $110(15)$ & $118(18)$ & $116(17)$ \\
\hline Diastolic & $66(7)^{*}$ & $71(14)$ & $72(8)$ \\
\hline Smoking (n (\%)) & 0 & $1(6 \%)$ & $6(23 \%)$ \\
\hline Pack years & & 0.5 & $4.5(3$ to 8$)$ \\
\hline Diabetes (n) & 0 & 1 & 0 \\
\hline \multicolumn{4}{|l|}{ Cholesterol } \\
\hline Total $(\mathrm{mmol} / \mathrm{l})$ & $5.82(0.87)$ & $5.41(0.90)$ & $5.58(1.14)$ \\
\hline LDL (mmol/l) & $3.89(0.74)$ & $3.68(0.84)$ & $3.67(1.1)$ \\
\hline $\mathrm{HDL}(\mathrm{mmol} / \mathrm{l})$ & $1.21(0.34)$ & $0.97(0.30)^{*}$ & $1.17(0.26)$ \\
\hline Triglycerides (mmol/l) & $1.62(1.24)$ & $1.81(0.74)$ & $2.03(2.36)$ \\
\hline Family history of cardiovascular disease (n (\%)) & $1(8)$ & $5(29)$ & $8(31)$ \\
\hline Duration (months) & $85(18$ to 161$)$ & $43(29$ to 80$)$ & \\
\hline Generalised disease (n (\%)) & $7(58 \%)$ & $13(76 \%)$ & \\
\hline Proteinuria (mg/l) & $0.3(0$ to 0.5$)$ & $0.2(0$ to 0.65$)$ & \\
\hline Creatinine clearance $(\mathrm{ml} / \mathrm{min})$ & $85(28)$ & $82(30)$ & \\
\hline Patients with exacerbation (n) & 9 & 8 & \\
\hline Number of exacerbations & $2(0$ to 3$)+$ & $0(0$ to 1.5$)$ & \\
\hline Cumulative BVAS & $36.5(20.1)$ & $33.6(14.9)$ & \\
\hline (cum BVAS/duration in months) & $0.75(0.60)$ & $0.89(0.84)$ & \\
\hline Prednisolone use (n) & 11 & 16 & \\
\hline Cumulative prednisolone dose (g) & 15 (9 to 38$)$ & $16(11$ to 24$)$ & \\
\hline \multicolumn{4}{|l|}{ Cumulative prednisolone dose $(\mathrm{mg} /$ duration in } \\
\hline Antihypertensive agents ( $\mathrm{n}$ ) & 2 & 3 & 0 \\
\hline HMG-CoA inhibitors (n) & 0 & $4^{*}$ & 0 \\
\hline $\mathrm{hsCRP}_{(\mathrm{mg} / \mathrm{l})}$ & $1.8(0.8 \text { to } 7.0)^{*}$ & $3.2(1.6 \text { to } 7.2)^{\star *}$ & $1.2(0.16$ to 0.66$)$ \\
\hline $\mathrm{TM}$ (ng/ml) & $3.0(2.0$ to 4.5$)$ & $3.4(2.5$ to 5.4$)$ & $4.02(2.47$ to 5.4$)$ \\
\hline VCAM-1 (ng/ml) & $413(165)$ & $462(106)$ & $404(95)$ \\
\hline vWF (\%) & 119 (38 to 187$)$ & 73 (32 to 177$)$ & $68(30$ to 116$)$ \\
\hline MMP-3 (ng/ml) & $63.6(51.6 \text { to } 128.7)^{*}$ & $60.4(45.8 \text { to } 79.4)^{*}$ & $43.3(23.1$ to 58.6$)$ \\
\hline MMP-9 (ng/ml) & 502 (309) & $578(347)^{*}$ & $347(124)$ \\
\hline TIMP-1 (ng/ml) & $296(118)$ & $316(79)^{* *}$ & $238(48)$ \\
\hline
\end{tabular}

Values are mean (SD), $\mathrm{n}(\%)$, or median (25th to 75 th centile) unless specified.

Intima-media thickness (IMT) was considered to be increased when it exceeding $0.8 \mathrm{~mm}$ at the age of 50 and $0.9 \mathrm{~mm}$ in subjects over 50 . ${ }^{*} \mathrm{p}<0.05 v$ controls.

$\mathrm{tp}<0.05 \vee$ Wegener's granulomatosis patients with increased IMT.

${ }^{* *} \mathrm{p}<0.01 v$ controls.

BVAS, Birmingham vasculitis activity score; $H D L$, high density lipoprotein; hsCRP, high sensitivity $C$ reactive protein; $L D L$, low density lipoprotein; $M M P$, matrix metalloproteinase; TIMP, tissue inhibitor of metalloproteinase; TM, thrombomodulin; VCAM-1, vascular cell adhesion molecule-1; vWF, von Willebrand factor.

techniques, B mode and $\mathrm{M}$ mode. The B mode technique provides an image of the whole arterial segment, which allows assessment of a maximum IMT value over a segment and is thus suited to detection of the often initially focal increase in vessel wall thickness in early atherosclerosis. In our correlation analysis with risk factors we used maximum IMT values and not mean values to detect correlations between other variables. M mode IMT is the IMT at a discrete arterial position and has the advantage of a greater accuracy of measurement. It is thus able to detect smaller intergroup differences in IMT. Overall, there is good agreement between WTS-IMT and the mean B mode IMT. ${ }^{31}$ Also, our data showed a strong correlation between $\mathrm{B}$ mode and $\mathrm{M}$ mode (mean difference $=0.06 \mathrm{~mm}$, range -0.09 to 0.43 ) .

To determine predisposing factors for atherosclerosis in our patient group, traditional and non-traditional risk factors were investigated. Although the prevalence of traditional risk factors did not differ significantly between patients and controls, patients tended to be slightly older and to have a higher body mass index and blood pressure, and were more likely to be male and to have a family history of cardiovascular disease. Thus in addition we compared the prevalence of traditional risk factors in patients with an increased IMT with controls. Only HDL concentrations were lower in patients. Smoking tended to be more prevalent in controls and other risk factors did not differ significantly. Overall, risk factors between the two groups seemed to be equally distributed, suggesting again that disease related factors predispose for the development of atherosclerosis. However, because of the limited number of patients included in our study, no multivariate analyses could be undertaken. To investigate whether WG is an independent risk factor for accelerated development of atherosclerosis, prospective studies in a larger population need to be done. To determine the extent of endothelial activation, which might be one of the first steps in the development of atherosclerosis, concentrations of thrombomodulin, sVCAM-1, and vWF were measured. The values tended to be higher in patients with inactive disease, especially for vWF $(p=0.11)$, suggesting low grade chronic endothelial activation. ${ }^{14}$

Atherosclerosis is considered to be a chronic inflammatory disorder, and $\mathrm{C}$ reactive protein-a marker of systemic inflammation-is described as an independent prognostic marker for cardiovascular disease. In our patients, plasma concentrations of hsCRP were increased. Several studies have suggested that $\mathrm{C}$ reactive protein may contribute directly to the development of atherosclerosis, as it induces expression of adhesion molecules on the endothelial surface and promotes the adherence of leucocytes. ${ }^{32}{ }^{33}$ Thus $\mathrm{C}$ reactive protein could be a direct link between autoimmune disease, which is characterised by systemic inflammation, and an increased risk for cardiovascular disease.

Another important process in atherosclerosis is vascular remodelling in which MMPs play a major role. Excessive 
tissue remodelling and increased MMP activity have been demonstrated during atherosclerotic lesion progression including plaque disruption. Increased levels of MMP-1, MMP-3, MMP-9, and TIMP-1 are found in human atherosclerotic plaques. ${ }^{24}$ Also, increased serum concentrations of MMPs have been detected in acute coronary syndromes. ${ }^{34-36}$ Various cells present in plaques produce these MMPs, including smooth muscle cells and basophils, but the major source is the activated macrophage. Stimuli for synthesis are cytokines, which are inflammatory mediators. Thus some studies suggest that MMP values can also be used as markers of disease activity, for example in rheumatoid arthritis, ${ }^{37} 38$ Takayasu arteritis, ${ }^{39}$ and giant cell arteritis. ${ }^{40}$ We found increased levels of MMP-3, MMP-9, and TIMP-1 in our patients as well. The question remains as to whether this is a reflection of the greater prevalence of atherosclerotic changes in the vessel wall or of smouldering disease activity in these patients, which results in endothelial activation and, eventually, in atherosclerosis.

When we divided our patient group on the basis of the presence or absence of increased IMT, no differences were found in the prevalence of traditional or non-traditional risk factors, except for the number of exacerbations. We had expected to find a history of more severe disease in patients with increased IMT. In contrast, patients with lower IMT experienced more exacerbations than those with increased IMT. This finding is unexplained. Others have suggested that patients with exacerbations should be treated more aggressively with immunosuppressive drugs, resulting in prolonged disappearance of chronically low grade inflammation and endothelial cell activation. ${ }^{12}$ However, in the present study no difference was found in the cumulative dose of prednisolone between patients with and without increased IMT.

\section{Conclusions}

IMT is increased in patients with Wegener's granulomatosis compared with controls. This cannot be explained by an increased prevalence of traditional risk factors. Although endothelial activation markers in patients with inactive disease only showed a trend to an increase, the levels of hsCRP, MMPs, and TIMP-1 were raised. Whether this resulted from atherosclerosis or indicated ongoing smouldering disease activity has to be analysed further. However, until those studies have been done, intervention is recommended when traditional risk factors are present in order to prevent cardiovascular disease in these patients.

\section{Authors' affiliations \\ K de Leeuw, J-S Sanders, C G Kallenberg, M Bijl, Department of Clinical Immunology, University Hospital, Groningen, Netherlands C Stegeman, Department of Nephrology, University Hospital, Groningen \\ A Smit, Department of Vascular diseases, University Hospital, Groningen}

\section{REFERENCES}

1 Libby $\mathbf{P}$, Ridker PM, Maseri A. Inflammation and atherosclerosis. Circulation 2002; 105:1135-43.

2 Ross R. Atherosclerosis - an inflammatory disease. N Engl J Med 1999;340:115-26.

3 Shimokawa $\mathrm{H}$. Primary endothelial dysfunction: atherosclerosis. J Mol Cell Cardiol 1999;31:23-37.

4 Szmitko PE, Wang CH, Weisel RD, de Almeida JR, Anderson TJ, Verma S. New markers of inflammation and endothelial cell activation. Part I. Circulation 2003;108:1917-23.

5 Albert MA, Glynn RJ, Ridker PM. Plasma concentration of C-reactive protein and the calculated Framingham coronary heart disease risk score. Circulation 2003; 108:161-5

6 Ridker PM, Hennekens CH, Buring JE, Rifai N. C-reactive protein and other markers of inflammation in the prediction of cardiovascular disease in women. N Engl J Med 2000;342:836-43.
7 Ridker PM, Rifai N, Rose L, Buring JE, Cook NR. Comparison of C-reactive protein and low-density lipoprotein cholesterol levels in the prediction of first cardiovascular events. N Engl J Med 2002:347:1557-65.

8 Alkaabi JK, Ho M, Levison R, Pullar T, Belch JJ. Rheumatoid arthritis and macrovascular disease. Rheumatology (Oxford) 2003;42:292-7.

9 Del Rincon I, Williams K, Stern MP, Freeman GL, O'Leary DH, Escalante A Association between carotid atherosclerosis and markers of inflammation in rheumatoid arthritis patients and healthy subjects. Arthritis Rheum 2003;48:1833-40.

10 Esdaile JM, Abrahamowicz M, Grodzicky T, Li Y, Panaritis C, du Berger R, et al. Traditional Framingham risk factors fail to fully account for accelerated atherosclerosis in systemic lupus erythematosus. Arthritis Rheum 2001:44:2331-7.

11 Gonzalez-Juanatey C, Llorca J, Testa A, Revuelta J, Garcia-Porrua C, Gonzalez-Gay MA. Increased prevalence of severe subclinical atherosclerotic findings in long-term treated rheumatoid arthritis patients without clinically evident atherosclerotic disease. Medicine (Baltimore) 2003:82:407-13.

12 Roman MJ, Shanker BA, Davis A, Lockshin MD, Sammaritano L, Simantov R, et al. Prevalence and correlates of accelerated atherosclerosis in systemic lupus erythematosus. N Engl J Med 2003;349:2399-406

13 Vlachoyiannopoulos PG, Kanellopoulos PG, loannidis JP, Tektonidou MG, Mastorakou I, Moutsopoulos HM. Atherosclerosis in premenopausal women with antiphospholipid syndrome and systemic lupus erythematosus: a controlled study. Rheumatology (Oxford) 2003;42:645-51.

14 Ara J, Mirapeix E, Arrizabalaga P, Rodriguez R, Ascaso C, Abellana R, et al. Circulating soluble adhesion molecules in ANCA-associated vasculitis. Nephrol Dial Transplant 2001;16:276-85.

15 Simantov R, Lo SK, Gharavi A, Sammaritano LR, Salmon JE, Silverstein RL. Antiphospholipid antibodies activate vascular endothelial cells. Lupus 1996:5:440-1.

16 Hoffman GS, Kerr GS, Leavitt RY, Hallahan CW, Lebovics RS, Travis WD, et al. Wegener granulomatosis: an analysis of 158 patients. Ann Intern Med 1992;116:488-98.

17 Muller Kobold AC, van Wijk RT, Franssen CF, Molema G, Kallenberg CG, Tervaert JW. In vitro up-regulation of E-selectin and induction of interleukin-6 in endothelial cells by autoantibodies in Wegener's granulomatosis and microscopic polyangiitis. Clin Exp Rheumatol 1999; 17:433-40.

18 Stegeman CA, Tervaert JW, Huitema MG, de Jong PE, Kallenberg CG. Serum levels of soluble adhesion molecules intercellular adhesion molecule 1, vascular cell adhesion molecule 1, and E-selectin in patients with Wegener's granulomatosis. Relationship to disease activity and relevance during followup. Arthritis Rheum 1994;37:1228-35.

19 Booth AD, Jayne DR, Kharbanda RK, McEniery CM, Mackenzie IS, Brown J et al. Infliximab improves endothelial dysfunction in systemic vasculitis: a model of vascular inflammation. Circulation 2004;109:1718-23.

20 Filer AD, Gardner-Medwin JM, Thambyrajah J, Raza K, Carruthers DM, Stevens RJ, et al. Diffuse endothelial dysfunction is common to ANCA associated systemic vasculitis and polyarteritis nodosa. Ann Rheum Dis 2003;62:162-7.

21 Booth AD, Wallace S, McEniery CM, Yasmin, Brown J, Jayne DR, et al. Inflammation and arterial stiffness in systemic vasculitis: a model of vascular inflammation. Arthritis Rheum 2004;50:581-8.

22 Faia KL, Davis WP, Marone AJ, Foxall TL. Matrix metalloproteinases and tissue inhibitors of metalloproteinases in hamster aortic atherosclerosis: correlation with in-situ zymography. Atherosclerosis 2002; 160:325-37.

23 Galis ZS, Khatri JJ. Matrix metalloproteinases in vascular remodeling and atherogenesis: the good, the bad, and the ugly. Circ Res 2002;90:251-62.

24 Orbe J, Fernandez L, Rodriguez JA, Rabago G, Belzunce M, Monasterio A, ef al. Different expression of MMPs/TIMP-1 in human atherosclerotic lesions. Relation to plaque features and vascular bed. Atherosclerosis 2003;170:269-76

25 Leavitt RY, Fauci AS, Bloch DA, Michel BA, Hunder GG, Arend WP, et al. The American College of Rheumatology 1990 criteria for the classification of Wegener's granulomatosis. Arthritis Rheum 1990;33:1101-7.

26 Luqmani RA, Bacon PA, Moots RJ, Janssen BA, Pall A, Emery P, et al. Birmingham Vasculitis Activity Score (BVAS) in systemic necrotizing vasculitis. QJM 1994;87:671-78.

27 van Leeuwen MA, van Rijswijk MH, Westra J, de Jong HJ, Marrink J. [C-reactive protein; an expensive sedimentation?]. Ned Tiidschr Geneeskd 1986;130:1391-5

28 de Groot E, Jukema JW, Montauban van Swijndregt $A D$, Zwinderman $A H$ Ackerstaff RG, van der Steen AF, et al. B-mode ultrasound assessment of pravastatin treatment effect on carotid and femoral artery walls and its correlations with coronary arteriographic findings: a report of the Regression Growth Evaluation Statin Study (REGRESS). J Am Coll Cardiol 1998;31:1561-7

29 Howard G, Sharrett AR, Heiss G, Evans GW, Chambless LE, Riley WA, et al. Carotid artery intimal-medial thickness distribution in general populations as evaluated by B-mode ultrasound. ARIC Investigators. Stroke 1993;24:1297-304.

30 Montauban van Swijndregt AD, De Lange EE, de Groot E, Ackerstaff RG. An in vivo evaluation of the reproducibility of intima-media thickness measurements of the carotid artery segments using B-mode ultrasound. measurements of the carotid artery segmer
Ultrasound Med Biol 1999;25:323-30.

31 Van Bortel LM, Vanmolkot FH, van der Heijden-Spek JJ, Bregu M, Staessen JA, Hoeks AP. Does B-mode common carotid artery intima-media thickness differ from M-model? Ultrasound Med Biol $2001 ; 27: 1333-6$.

32 Khreiss T, Jozsef L, Potempa LA, Filep JG. Conformational rearrangement in $\mathrm{C}$-reactive protein is required for proinflammatory actions on human endothelial cells. Circulation 2004;109:2016-22. 
33 Pasceri V, Willerson JT, Yeh ET. Direct proinflammatory effect of C-reactive protein on human endothelial cells. Circulation 2000;102:2165-8.

34 Kai H, Ikeda H, Yasukawa H, Kai M, Seki Y, Kuwahara F, et al. Peripheral blood levels of matrix metalloproteases -2 and -9 are elevated in patients with acute coronary syndromes. J Am Coll Cardiol 1998;32:368-72

35 Nomoto K, Oguchi S, Watanabe I, Kushiro T, Kanmatsuse K. Involvement of inflammation in acute coronary syndromes assessed by levels of highsensitivity C-reactive protein, matrix metalloproteinase- 9 and soluble vascularcell adhesion molecule-1. J Cardiol 2003;42:201-6.

36 Tziakas DN, Chalikias GK, Parissis JT, Hatzinikolaou El, Papadopoulos ED, Tripsiannis GA, et al. Serum profiles of matrix metalloproteinases and their tissue inhibitor in patients with acute coronary syndromes. The effects of shortterm atorvastatin administration. Int J Cardiol 2004;94:269-77.
37 Posthumus MD, Limburg PC, Westra J, van Leeuwen MA, van Rijswijk MH. Serum matrix metalloproteinase 3 in early rheumatoid arthritis is correlated with disease activity and radiological progression. J Rheumatol 2000;27:2761-8

38 Tchetverikov I, Lard LR, DeGroot J, Verziil N, TeKoppele JM, Breedveld FC, et al. Matrix metalloproteinases- $3,-8,-9$ as markers of disease activity and joint damage progression in early rheumatoid arthritis. Ann Rheum Dis 2003;62:1094-9.

39 Matsuyama A, Sakai N, Ishigami M, Hiraoka H, Kashine S, Hirata A, et al. Matrix metalloproteinases as novel disease markers in Takayasu arteritis. Circulation 2003;108:1469-73.

40 Sorbi D, French DL, Nuovo GJ, Kew RR, Arbeit LA, Gruber BL. Elevated levels of 92-kd type IV collagenase (matrix metalloproteinase 9) in giant cell arteritis. Arthritis Rheum 1996;39:1747-53.

\section{Get published within days of acceptance with ARD}

We are delighted to announce that the Annals of the Rheumatic Diseases launched a "publish ahead of print" programme in February 2004. Selected papers are fast tracked and published online months before they appear in the print journal.

Papers of major significance to the international rheumatology community are published within days of acceptance. The first published article is the raw accepted manuscript; edited and typeset versions are also published as soon as they are available.

In addition to being available on ARD Online, the publish ahead of print articles are searchable through PubMed/ Medline-establishing primacy for your work. They are linked from the ARD Online home page.

To take advantage of this "publish ahead of print" programme submit your papers to the Annals of the Rheumatic Diseases using our online submission and review system Bench > Press (http://submit-ard.bmijournals. com). For further information contact ARD@bmigroup.com. 